The generalisation of linguistic constructions in children with or without developmental language disorders.

KRZEMIEN Magali ${ }^{a}$, SERET Esther ${ }^{a}$ and MAILLART Christelle ${ }^{a}$

${ }^{a}$ Department of Speech and Language Therapy, Research Unit on Childhood, University of Liège

Correspondence: KRZEMIEN Magali, B.38b, 30 rue de l'Aunaie, 4000 Liège, Belgium, mkrzemien@alumni.uliege.be

Running headline: Construction generalisation in DLD.

Acknowledgments: We thank the children who participated in the study, as well as the parents, teachers, and speech-language therapists. This work was supported by the FRESH fund of the Fonds National de la Recherche Scientifique.

Keywords: Generalisation, constructions, developmental language disorders, inhibition. 


\title{
The generalisation of linguistic constructions in children with or without developmental language disorders.
}

\begin{abstract}
The generalisation of linguistic constructions is performed through analogical reasoning. Children with developmental language disorders (DLD) are impaired in analogical reasoning and in generalisation. However, these processes are improved by an input involving variability and similarity. Here we investigated the performance of children with or without DLD in a construction generalisation task. We also compared their performance following training with an input involving progressive alignment (combining similarity and variability) or high variability. Progressive alignment improves construction generalisation in children with or without DLD, which could have implications for our understanding of language development and for interventions conducted with children with DLD.
\end{abstract}

\section{Introduction}

Young children are confronted with several challenges when they learn language. One of which is acquiring constructions, which are "stored pairings of form and function" (Goldberg, 2003, p. 219). Constructions vary in their complexity and their degree of abstractness, as they range from idioms to general constructions, such as the passive construction (Tomasello, 2009), but they usually refer to a "morphosynctactically complex structure that is partially schematic" (Bybee, 2010, p. 76). Children progressively generalise concrete constructions to acquire abstract schemas (Cordes, 2016). The acquisition of constructions allows for linguistic productivity (Schmid, 2016), as the schematic positions in constructions are filled with new lexical items (Bybee, 2010). This productivity in language emerges through a domain-general process, analogy (Bybee, 2010; Cordes, 2016). Analogy refers to the identification of a common structure or relational pattern between two situations or contexts (Gentner \& Colhoun, 2010). In language learning, performing analogies between utterances allows for the abstraction of constructions (Tomasello, 2009). Analogy also refers to the process by which a new lexical item is used in a construction, thus improving linguistic productivity (Bybee, 2010). Analogical reasoning is, therefore, essential to construction generalisation (Bybee, 2010; Tomasello, 2009).

Analogy and generalisation can be facilitated by modifying the input which is presented to children. Input with high variability or high type frequency (i.e., the number of appearances of a specific structure in the input) have been shown to improve generalisation and, more precisely, construction generalisation (Bybee, 2010). Wonnacott, Boyd, Thomson, and Goldberg (2012) showed that five-yearold children generalised a novel construction better if the construction was presented with four different verbs than if it was presented with only one verb. In verb extension, Snape and Krott (2018a) observed that three-year-old children could extend new verbs when two exemplars were displayed but not when one exemplar was presented twice. Even in novel noun generalisation, Perry, Samuelson, Malloy, and Schiffer (2010) found that eighteen-month-old infants generalised new words when they had been trained with variable exemplars but not with highly similar exemplars of a lexical category. However, Casenhiser and Goldberg (2005) also found that too much variability could impair construction generalisation: in their study, children between five- and seven years old performed better in a construction generalisation task when the training involved skewed frequency (one verb presented four times plus four verbs presented once) than when it involved balanced frequency (three verbs presented twice plus two verbs presented once). Lexical similarity (i.e., the fact that utterances have some words in common) therefore seems to be beneficial for construction generalisation. 
Similarity is indeed a powerful way of improving analogical reasoning and generalisation: analogies are facilitated when the situations that have to be mapped are perceptually similar (see Cordes, 2016 for a review). Moreover, semantic similarity has been shown to facilitate structural priming, and so generalisation, in four-year-old children (Goldwater, Tomlinson, Echols, \& Love, 2011). Thus, variability and similarity improve analogical reasoning and generalisation. While these two variables seem to be incompatible, we were interested in combining them to maximise children's generalisation abilities. We used a principle called progressive alignment, which consists of presenting highly similar items at first, and continuing with progressively distinct items (Kotovsky \& Gentner, 1996). Thus, progressive alignment relies on similarity to begin with, while variability is gradually introduced. This process has been found to favour the identification of an abstract schema in analogical reasoning tasks, because comparison and alignment of similar items facilitate the subsequent alignment of structures containing dissimilar components (Kotovsky \& Gentner, 1996). Moreover, in word acquisition, progressive alignment has been shown to improve relational noun generalisation and verb extension in young children (Childers et al., 2016; Gentner, Anggoro, \& Klibanoff, 2011). Thus, progressive alignment facilitates analogical reasoning and word generalisation. However, to our knowledge, its impact on novel construction generalisation has never been studied. Given the positive influences that variability and similarity have on generalisation, it is likely that progressive alignment, which is a combination of these two aspects, favours the generalisation of novel constructions.

Construction generalisation might also be impacted by inhibition. Inhibition has indeed been related to analogical reasoning, especially when perceptual distractive information is introduced (Richland, Morrison, \& Holyoak, 2006; Thibaut, French, \& Vezneva, 2010). Moreover, word generalisation has been found to be influenced by inhibition: Snape and Krott (2018b) showed that inhibition predicted performance in a word extension task in which lexical categories were based on conceptual properties rather than on perceptual features. This relationship was independent of age and of general cognitive maturation. Inhibition therefore seems to play a role in analogical reasoning and in word generalisation, especially when concrete information has to be disregarded to the advantage of an abstract schema or category. Yet, we have already seen that construction generalisation relied on analogical reasoning. Thus, we were interested in examining the influence of inhibition on the generalisation of an abstract construction.

Children with developmental language disorder (DLD) particularly struggle with language acquisition. These children have language difficulties that are not related to biomedical conditions, such as an intellectual disability, a genetic condition, or a brain injury (Bishop et al., 2017). These children can have language disorders in production and comprehension, as well as in the different language components, but morphosyntax is particularly affected (Leonard, 2014). They have poor linguistic productivity and highly rely on the input that they hear (Jones \& Conti-Ramsden, 1997). They are impaired when they have to use morphemes and syntactic schemas productively (Conti-Ramsden \& Windfuhr, 2002; Leonard, Davis, \& Deevy, 2007). Even in vocabulary acquisition, children with DLD perform poorly when they must extend novel nouns (Collisson, Grela, Spaulding, Rueckl, \& Magnuson, 2015). However, to our knowledge, construction generalisation has never been directly studied in these children. Given the findings obtained for morphosyntax and vocabulary, it is probable that they also have generalisation difficulties for linguistic constructions.

DLD children's difficulty in generalising linguistic structures and lexical categories can be related to an analogical reasoning impairment (Leroy, Parisse, \& Maillart, 2014a): children with DLD perform worse than their peers without language disorders when they have to solve linguistic or nonlinguistic analogies, which could hinder their generalisation abilities (Leroy, Maillart, \& Parisse, 2014b; Leroy, 
Parisse, \& Maillart, 2012). They are especially impaired when analogies are not supported by similarity: if the situations that have to be mapped are perceptually similar, children with DLD perform as well as their peers, but they are impaired if they have to process relational features alone (Leroy et al. 2012; Leroy et al. 2014b). Moreover, children with DLD are impaired in a priming task when the prime and the target sentences do not have any words in common (Leroy et al., 2014a). They need similarity to perform analogies and to generalise linguistic or nonlinguistic schemas. However, children with DLD also benefit from an input involving variability. Plante et al. (2014) found that their learning of a new morpheme was improved if they had been trained with 24 different verbs instead of 12 . Adults with language impairment were also better at generalising an artificial grammar when they had been confronted with a high variability input (Von Koss Torkildsen, Dailey, Aguilar, Gómez, \& Plante, 2013). Even in word learning, Aguilar, Plante, and Sandoval (2018) found that preschool-aged children with DLD had better retention performance in learning and generalising new words with three different exemplars of the same category rather than with one exemplar presented three times. To conclude, some studies have shown a need for variability (Aguilar et al., 2018; Plante et al., 2014; Von Koss Torkildsen et al., 2013), while others have highlighted a benefit of similarity (Leroy et al., 2012; Leroy et al., 2014a; Leroy et al., 2014b) for generalisation and analogical reasoning in children with DLD. This benefit seems to be larger than for their peers without language disorders (Leroy et al., 2012; Leroy et al., 2014a; Von Koss et al., 2013). Even if no studies, to our knowledge, have investigated the influence of progressive alignment on analogical reasoning and generalisation in children with DLD, it is likely that these children benefit from an input combining similarity and variability.

Given these findings, our first objective was to evaluate construction generalisation in children with or without DLD. We assumed that language-matched children without language disorders outperform children with DLD in a construction generalisation task.

As a second objective, we wanted to evaluate the impact of a training input involving progressive alignment in comparison with an input with high variability. Based on previous results (Casenhiser \& Goldberg, 2005), we made the hypothesis that both groups benefit more from progressive alignment than from high variability and that this benefit is more important for children with DLD.

Finally, our last objective was to evaluate the impact of inhibition on the ability to abstract and generalise a novel linguistic construction, as inhibition has already been related to analogical reasoning and generalisation (Richland et al., 2006; Snape \& Krott, 2018b; Thibaut et al., 2010). We assumed that inhibition ability, as measured by a classical inhibition task, is a significant predictor of performance in a construction generalisation task.

\section{Method}

\section{Participants}

Sixty children were recruited in the French-speaking region of Belgium for this study, which received the approval of the local ethics committee. Informed consent forms were distributed to parents through schools, as well as questionnaires about the children's medical and developmental history. Children older than eight years old also had to sign an informed consent form to participate in the study, while children younger than eight years old transmitted their consent orally to the experimenter. All of the recruited children were monolingual, as bilingualism could have influenced the language evaluation. No participating children had a hearing impairment or a neurological 
disorder, and they all had a non-verbal intellectual quotient higher than 80 (Non-verbal Wechsler, Wechsler \& Naglieri, 2009), thus attesting for the absence of intellectual disability. Finally, a language evaluation was administered to each child. Receptive abilities were assessed with picture-pointing tasks involving words for vocabulary (Evaluation du Vocabulaire en Images Peabody, EVIP, Dunn, Thériault-Whalen, \& Dunn, 1993) and sentences for morphosyntax (Epreuve de COmpréhension Syntaxico-SEmantique, ECOSSE, Lecocq, 1996). Expressive abilities were evaluated with the ELO battery (Evaluation du Langage Oral, Khomsi, 2001), with a word repetition task in phonology, a picture-naming task in vocabulary, and a sentence completion task in morphosyntax.

Thirty children had been diagnosed with DLD previous to the study. Moreover, the language evaluation confirmed these diagnoses, as children with DLD all had at least two language components below the $10^{\text {th }}$ percentile, thus respecting Leonard's criteria (2014). However, the language impairment was often more severe than that, with a mean $\mathrm{Z}$ score of $-4.20 \sigma$ for the whole group. Expressive phonological and morphosyntactical abilities were mostly impaired, as all children except one were below the $10^{\text {th }}$ percentile in these domains. Thirty TD children were matched to children with DLD on a measure of sentence comprehension ( \pm 3 errors, ECOSSE, Lecocq, 1996). Children with DLD are usually matched to TD children on an expressive measure, such as the mean length of utterance, in studies investigating generalisation (Hansson \& Leonard, 2003; Leonard et al., 2007; Vang Christensen \& Hansson, 2012). However, contrary to these studies, we evaluated generalisation in comprehension and not in expression. We therefore used a comprehension measure to match our two groups. Moreover, children with DLD are regularly impaired compared to TD children matched on a morphosyntactic measure in generalisation tasks or in tasks evaluating complex structures, because these aspects are particularly weak in DLD, even when general language abilites are considered (Hansson \& Leonard, 2003; Leonard et al., 2007; Souto, Leonard, Deevy, Fey, \& Bredin-Oja, 2016). Finally, with this matching procedure we will neutralise the impact that verbal comprehension could have on generalisation, and so, we will evaluate the specific contribution of generalisation in language acquisition. TD children had never repeated a year at school and had no history of language impairment. Moreover, they performed above the $10^{\text {th }}$ percentile in all the language domains evaluated. The two groups did not differ on gender, non-verbal intellectual quotient, or word and sentence comprehension (for raw scores), but they differed on age and all expressive language measures. These data are reported in Table 1. Each child with DLD, as well as his/her language-matched peer, were randomly assigned to one of the two training conditions (progressive alignment or high variability). In the two training conditions, TD children were significantly younger $(p<.001)$ and had a similar comprehension ability $(p>.10)$ as children with DLD. 
Table 1

Characteristics of the groups

\begin{tabular}{|c|c|c|c|}
\hline & $\begin{array}{l}\text { Children with DLD } \\
\quad(n=30)\end{array}$ & $\begin{array}{l}\text { Language-matched } \\
\text { children }(n=30)\end{array}$ & \\
\hline Gender & 9 girls; 21 boys & 12 girls; 18 boys & $X^{2}(2)=2.46$ \\
\hline \multicolumn{4}{|l|}{ Age } \\
\hline Years;months (SD) & $9 ; 11(1 ; 8)$ & $7 ; 7(2 ; 1)$ & $t(58)=-4.67 * * *$ \\
\hline \multicolumn{4}{|l|}{ NVIQ } \\
\hline Mean (SD) & $94.1(10.1)$ & $99.1(12.3)$ & $W=565$ \\
\hline \multicolumn{4}{|l|}{ Word repetition } \\
\hline Raw score - Mean (SD) & $23.2(6.74)$ & $29.2(5.81)$ & $W=767 * * *$ \\
\hline Z score - Mean (SD) & $-13.4(12.5)$ & $0.73(0.37)$ & $W=900 * * *$ \\
\hline \multicolumn{4}{|l|}{ Picture pointing (word) } \\
\hline Raw score - Mean (SD) & $87.9(19.1)$ & $94.0(28.8)$ & $t(50.4)=0.97$ \\
\hline Z score - Mean (SD) & $87.2(12.2)$ & $114(9.45)$ & $t(58)=9.54 * * *$ \\
\hline \multicolumn{4}{|l|}{ Picture naming } \\
\hline Raw score - Mean (SD) & $29.6(4.80)$ & 33.1 (7.09) & $W=588^{*}$ \\
\hline Z score - Mean (SD) & $-1.16(0.96)$ & $0.64(0.67)$ & $W=875^{* * *}$ \\
\hline \multicolumn{4}{|c|}{ Picture pointing (sentence) } \\
\hline Error score - Mean (SD) & $14.1(7.31)$ & $12.6(8.17)$ & $t(58)=-0.73$ \\
\hline Z score - Mean (SD) & $-1.28(1.04)$ & $0.13(0.67)$ & $t(58)=6.27^{* * *}$ \\
\hline \multicolumn{4}{|l|}{ Sentence completion } \\
\hline Raw score - Mean (SD) & $12.5(4.98)$ & $16.5(5.06)$ & $t(58)=3.09 * *$ \\
\hline Z score - Mean (SD) & $-4.32(1.88)$ & $-0.16(0.71)$ & $t(37.1)=11.3^{* * *}$ \\
\hline
\end{tabular}

Note. $\mathrm{DLD}=$ developmental language disorders, $\mathrm{SD}=$ standard deviation, $\mathrm{NVIQ}=$ non-verbal intellectual quotient, $* p<.05,{ }^{* *} p<.01, * * * p<.001$.

\section{Material and procedure}

We created a construction generalisation task according to the protocol used by Casenhiser and Goldberg (2005), except that our training conditions differed from the conditions used in their study. A NP-NP-V (Noun Phrase-Noun Phrase-Verb) structure was associated with a meaning of appearance (i.e., something appears in a specific place). The NP-NP-V structure corresponds to the meaning of appearance, while the NPs and the $V$ contains additional information: the first NP is the character who appears. The second NP is the specific place where the character appears and the $\mathrm{V}$ contains details about how this character appears (e.g., jumping or sliding). These structure and meaning do not exist in French constructions, which allowed us to examine the learning and generalisation of a novel construction in our participants. A sentence was associated with a video in which figurines performed various actions. Nouns were frequent French nouns $(M=239$ occurrences for a million words, $S D=$ 208, according to Manulex database, Lété, Sprenger-Charolles, \& Colé, 2004). Verbs were non-words created according to a Consonant-Vowel-Consonant-Vowel structure, which is frequently used in French. Each syllable had a high phonotactic frequency $(M=3033$ occurrences for a million words, $S D$ $=6873$, according to Manulex database, Lété et al., 2004). Figurines were moved with transparent 
strings. For example, in the sentence Le chat la ferme sanfe ('the cat the farm sanfe'), a cat appeared in front of a farm while jumping (see Figure 1). The sentence was presented in the present tense at the beginning of the video and in the past tense at the end of the video. The past tense used was the passé composé, a frequent French verb form in which an auxiliary verb is added before the verb inflected with the -é ending (e.g., sanfe in the present tense and a sanfé in the past tense).

Figure 1

Screenshot of the video in which a cat appears while jumping in the direction of the farm

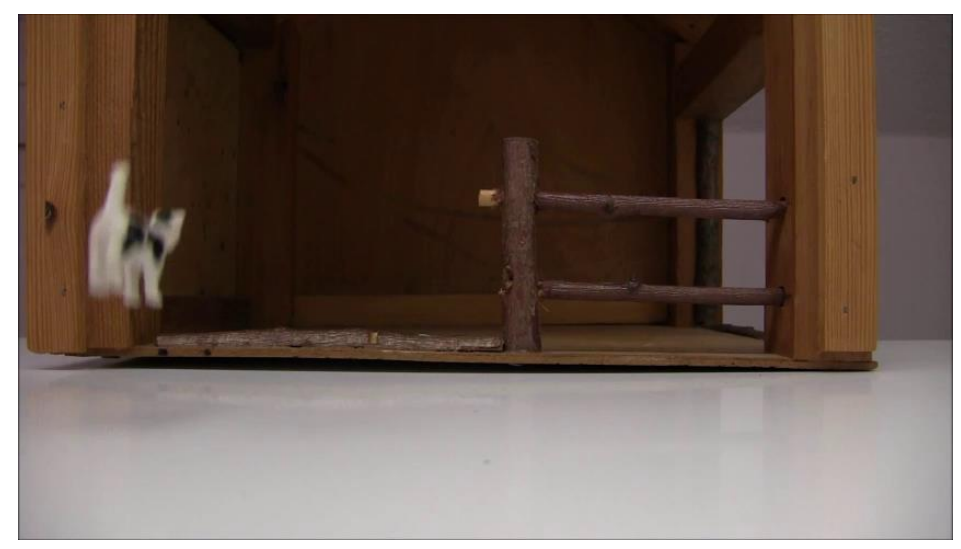

For the high variability condition, eight sentences that had no words in common were created. For the progressive alignment condition, the second, third, fourth, and fifth sentences were replaced with sentences that had words in common and were progressively distinct. All of the sentences used in the two training conditions are reported in Table 2. During the testing phase, twelve additional sentences were presented to the children. These sentences did not have any common words or non-words with the stimuli of the training phase. Six of the sentences were constructed according to the novel construction, and the other six were transitive sentences with a NP-V-NP structure and a meaning involving someone performing an action towards somebody or something. Each sentence was presented with two videos, one picturing the novel construction meaning (i.e., a figurine appears in a specific environment), and one picturing the transitive meaning (i.e., a figurine performs an action using the same environment as in the novel construction video). Transitive sentences were used to see if children could differentiate the novel construction from a construction that they already knew. If we would have used only NP-NP-V sentences, children might have always selected the video picturing the novel meaning, without identifying the relationship between the novel structure and its function. Here again, the sentence was presented in the present tense at the beginning of the video and in the past tense at the end of the video.

The task was presented on a computer using OpenSesame software (Mathôt, Schreij, \& Theeuwes, 2012) and lasted for about 15 minutes. The training phase was introduced with an entertaining context: the child was told that a small alien wanted to teach him/her his language and that $\mathrm{s} / \mathrm{he}$ had to look and listen carefully. Then, the sequence of eight training stimuli was presented twice. Before the testing phase, the child was asked to select the video which corresponded best to the sentence that $s /$ he heard. Then, the testing phase began. As the two videos were presented simultaneously, participants could see them several times and stopped them when they responded by pressing the corresponding key. No feedback was provided, except for neutral encouragement. 
Table 2

Training stimuli according to the training condition

\begin{tabular}{|c|c|c|c|}
\hline \multicolumn{2}{|c|}{ High variability } & \multicolumn{2}{|c|}{ Progressive alignment } \\
\hline Sentence & Meaning & Sentence & Meaning \\
\hline $\begin{array}{l}\text { Le chat la ferme sanfe. } \\
\text { 'The cat the farm sanfe.' }\end{array}$ & $\begin{array}{l}\text { The cat appears } \\
\text { while jumping in the } \\
\text { direction of the farm. }\end{array}$ & $\begin{array}{l}\text { Le chat la ferme sanfe. } \\
\text { 'The cat the farm sanfe.' }\end{array}$ & $\begin{array}{l}\text { The cat appears while } \\
\text { jumping in the } \\
\text { direction of the farm. }\end{array}$ \\
\hline $\begin{array}{l}\text { L'homme le cheval lane. } \\
\text { 'The man the horse lane.' }\end{array}$ & $\begin{array}{c}\text { The man appears } \\
\text { while riding the } \\
\text { horse. }\end{array}$ & $\begin{array}{l}\text { Le chat la roue sanfe. } \\
\text { 'The cat the wheel sanfe.' }\end{array}$ & $\begin{array}{l}\text { The cat appears while } \\
\text { jumping in the } \\
\text { direction of the wheel. }\end{array}$ \\
\hline $\begin{array}{l}\text { Le canard la mare chonde. } \\
\text { 'The duck the pond } \\
\text { chonde.' }\end{array}$ & $\begin{array}{l}\text { The duck appears } \\
\text { while slipping in the } \\
\text { pond. }\end{array}$ & $\begin{array}{l}\text { Le chat la table sanfe. } \\
\text { 'The cat the table sanfe.' }\end{array}$ & $\begin{array}{c}\text { The cat appears while } \\
\text { jumping in the } \\
\text { direction of the table. }\end{array}$ \\
\hline $\begin{array}{l}\text { La fille la chaise mude. } \\
\text { 'The girl the chair mude.' }\end{array}$ & $\begin{array}{c}\text { The girl appears } \\
\text { while crawling near } \\
\text { the chair. }\end{array}$ & $\begin{array}{c}\text { La poule la table sanfe. } \\
\text { 'The chicken the table } \\
\text { sanfe.' }\end{array}$ & $\begin{array}{l}\text { The chicken appears } \\
\text { while jumping in the } \\
\text { direction of the table. }\end{array}$ \\
\hline $\begin{array}{l}\text { La vache le cochon manre. } \\
\text { 'The cow the pig manre.' }\end{array}$ & $\begin{array}{l}\text { The cow appears } \\
\text { while sliding next to } \\
\text { the pig. }\end{array}$ & $\begin{array}{l}\text { La poule le chapeau tade. } \\
\text { 'The chicken the hat tade.' }\end{array}$ & $\begin{array}{c}\text { The chicken appears } \\
\text { while hopping near the } \\
\text { hat. }\end{array}$ \\
\hline $\begin{array}{c}\text { Le garçon la brouette tade. } \\
\text { 'The boy the wheelbarrow } \\
\text { tade.' }\end{array}$ & $\begin{array}{l}\text { The boy appears } \\
\text { while bouncing into } \\
\text { the wheelbarrow. }\end{array}$ & $\begin{array}{c}\text { Le garçon la brouette tade. } \\
\text { 'The boy the wheelbarrow } \\
\text { tade.' }\end{array}$ & $\begin{array}{c}\text { The boy appears while } \\
\text { bouncing into the } \\
\text { wheelbarrow. }\end{array}$ \\
\hline $\begin{array}{c}\text { La dame le sac pobe. } \\
\text { 'The woman the bag } \\
\text { pobe.' }\end{array}$ & $\begin{array}{c}\text { The woman appears } \\
\text { while moving next to } \\
\text { the bag. }\end{array}$ & $\begin{array}{l}\text { La dame le sac pobe. } \\
\text { 'The woman the bag pobe.' }\end{array}$ & $\begin{array}{c}\text { The woman appears } \\
\text { while moving next to } \\
\text { the bag. }\end{array}$ \\
\hline $\begin{array}{l}\text { L'oiseau le jardin tufe. } \\
\text { 'The bird the garden tufe.' }\end{array}$ & $\begin{array}{l}\text { The bird appears } \\
\text { while flying above } \\
\text { the garden. }\end{array}$ & $\begin{array}{l}\text { L'oiseau le jardin tufe. } \\
\text { 'The bird the garden tufe.' }\end{array}$ & $\begin{array}{l}\text { The bird appears while } \\
\text { flying above the } \\
\text { garden. }\end{array}$ \\
\hline
\end{tabular}

In addition to the experimental task, we also assessed participants' inhibition capacity. Indeed, this function is helpful to analogical reasoning and to word extension, especially when a schema or a category has to be abstracted while resisting to perceptual cues (Richland et al., 2006; Snape \& Krott, 2018b; Thibaut et al., 2010). We therefore supposed that it could also influence construction generalisation. Inhibition was evaluated with a 'Go-NoGo' task in which participants have to push the space bar when the target stimulus appears on the screen while withholding from responding when another stimulus appears. In the task that we used, children had to push the space bar when a red cat appeared ('Go' signals) while not responding when a gray cat appeared ('NoGo' signals, Geurten, Catale, \& Meulemans, 2016). There was a training phase for the child to get familiar with the instructions and the task. The testing phase contained 20 'Go' and 20 'NoGo' signals for which no feedback was provided. The inhibition measure was the percentage of correct responses. The task was administered according to the standardisation conditions, on a computer using E-Prime 2.0 (Psychology Software Tools Inc., 2012). 


\section{Results}

\section{Response scores}

A factorial analysis of variance $(2 \times 2)$ with the group (children with DLD vs. TD children) and the training condition (high variability vs. progressive alignment) as between-subject factors and the construction (novel vs. transitive) as a within-subject factor was conducted on the number of correct responses. We considered both transitivity and novel construction items because, in addition to children's abilities to generalise a novel construction, we wanted to analyse the impact of a novel construction learning on the knowledge and generalisation of a known construction: it is possible that children would overgeneralise the novel construction to the transitivity construction and that the better the novel construction is generalised, the worse the transitivity construction is. Data are reported in Table 3. The effect of the group did not reach significance, $F(1,56)=1.75, p=.19, \eta^{2}{ }_{p}=.030$, as the two groups had similar performance. However, the effect of the training condition was significant, $F(1,56)=15.7, p<$ $.001, \eta_{p}^{2}=.22$ : children in the progressive alignment condition performed better than children in the high variability condition. The effect of the construction also reached significance, $F(1,56)=42.6, p<$ $.001, \eta_{p}^{2}=.43$, as the transitivity items were better performed than the novel construction items, suggesting that children did not overgeneralise the novel structure learning. Finally, the analysis did not reveal any significant interaction (all $p>.33$ ), which means notably that the effect of the condition was similar in the two groups and for the two constructions. Results are displayed in Figure 2. We also conducted one-sample t-tests on the number of correct responses for each group and each training condition to examine if the scores differed from chance level (50\%). For transitivity items, performance was above chance level for each group and each training condition (all $p<.022$ ). For novel construction items, performance was at chance level for each group and training condition (all $p>.10$ ), except for children with DLD in the high variability condition who performed below chance level, $t(14)=-2.69, p$ $=.017$. The analyses on the total scores led to more interesting results: it revealed that both groups in the progressive alignment condition responded above chance level, $t(14)=3.86, p=.002$ for DLD children and $t(14)=5.53, p<.001$ for TD children. However, the performance of the two groups in the high variability condition did not differ from chance level, $t(14)=0.48, p=.64$ for children with DLD and $t(14)=0.81, p=.43$ for TD children.

Table 3

Percentage of correct responses as a function of the group and the training conditions

\begin{tabular}{llccc}
\hline & & $\begin{array}{c}\text { Novel } \\
\text { construction items }\end{array}$ & Transitivity items & Total \\
\cline { 3 - 5 } $\begin{array}{l}\text { Language- } \\
\text { matched }\end{array}$ & Progressive alignment & $58.9(19.8)$ & $80.0(20.1)$ & $69.4(13.6)$ \\
children & High variability & $41.1(22.6)$ & $64.4(21.7)$ & $52.8(13.2)$ \\
$\begin{array}{l}\text { Children with } \\
\text { DLD }\end{array}$ & Progressive alignment & $48.9(18.3)$ & $74.4(15.3)$ & $61.7(11.7)$ \\
& High variability & $35.6(20.8)$ & $67.8(20.4)$ & $51.7(13.4)$ \\
\hline
\end{tabular}

Note. DLD = developmental language disorders. 
Figure 2

Percentage of correct responses as a function of the training condition

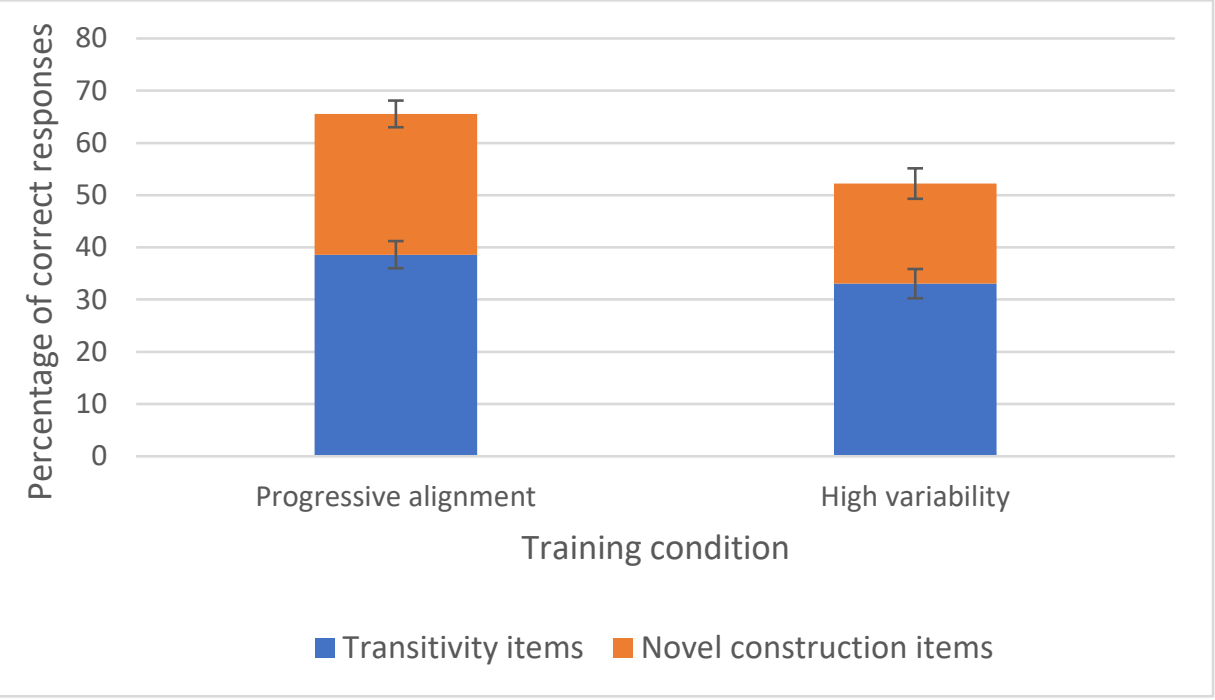

\section{Relation with inhibition}

The inhibition measure was the percentage of correct responses in the inhibition task $(M=89.7, S D=$ 10.1 for the DLD group; $M=86.7, S D=12.0$ for the TD group; $M=88.2, S D=11.1$ for both groups). No differences appeared between the DLD and TD groups, $t(58)=-1.09, p=.28, d=-0.28$. Interestingly, the inhibition measure correlated with the novel construction score, $r(58)=.29, p=.025$, but not with the transitivity score, $r(58)=.052, p=.69$. We therefore added the inhibition measure to the model to test whether it predicted the scores and if it could account for the effect of the training condition. Given the results of the correlational analysis, we conducted the analysis on the novel construction items and on the transitivity items separately. We analysed covariance $(2 \times 2)$ with the group (children with DLD vs. TD children) and the training condition (high variability vs. progressive alignment) as between-subject factors and the inhibition measure as a covariate on the novel construction scores on the one hand, and on the transitivity scores on the other hand. For the transitivity items, the effect of the training condition remained significant, $F(1,55)=4.78, p=.033, \eta_{p}{ }_{p}=.077$, while the inhibition measure had no significant influence on performance, $F(1,55)=0.022, p=.88, \eta^{2}{ }_{p}<.001$. This was not surprising given the results of the correlational analysis. However, for the novel construction items, inhibition had a significant impact on performance, $F(1,55)=5.75, p=.020, \eta^{2}{ }_{p}=.094$. Moreover, the effect of the training condition also remained significant, $F(1,55)=9.43, p=.003, \eta^{2}{ }_{p}=.12$. Finally, the effect of the group and the interaction between the group and the condition did not reach significance in the two analyses $(p>.13)$.

\section{Discussion}

We used a novel construction generalisation task to examine the ability of children with DLD to generalise a novel construction compared to TD children matched on a language measure. In contrast with our hypothesis, both groups obtained similar performance. Moreover, both groups obtained better performance for transitivity items than for novel construction items. This is not surprising as the transitive construction is supposed to be mastered by the participants, while the novel construction has just been presented to them. Moreover, children did not overgeneralise the novel structure 
learning, as we suggested. This also means that children with DLD generalise known and novel constructions as their language-matched peers. Thus, children with DLD seem to have difficulty in generalising constructions, but this difficulty is not more severe than their general language abilities. This is not consistent with several studies that have shown that children with DLD have worse performance than language-matched peers when they have to use syntactic schemas or morphemes productively (Conti-Ramsden \& Windfuhr, 2002; Leonard et al., 2007). However, in these studies, children with DLD were preschool-aged children of about 5 years old who were compared with control children of about 3 years old. Our groups were largely older, as children with DLD were school-aged children of about 10 years old while control children were around 7;6 years old. Group differences might be less salient at this age, as children with DLD might have caught up their language-matched peers, at least for some aspects of language acquisition. Moreover, studies investigating generalisation in adult participants with language disabilities have only compared participants' performance with a control group matched on age (Plante, Gómez, \& Gerken, 2002; Von Koss Torkilsden et al., 2013). These studies found differences between the two groups, as control participants outperformed the languageimpaired groups, but they cannot state if the generalisation abilities of adults with language-learning disabilities match their general language level. Finally, our two groups were matched on receptive abilities, but children with DLD performed worse than their peers in expressive tasks during the language assessment. As we only measured comprehension in our generalisation task, it is possible that group differences would have appeared if we had focused on expressive abilities.

We also compared two training conditions to evaluate construction generalisation, one with an input involving high variability (no words in common between all the stimuli) and one with an input involving progressive alignment (some words are similar at first, and variability is progressively introduced). We found that progressive alignment led to better performance than high variability. Our study is, to our knowledge, the first to show a positive influence of progressive alignment on construction generalisation. Interestingly, progressive alignment was beneficial not only for the generalisation of the novel construction, but also for the transitive construction. This was not particularly expected, but this shows that learning a novel construction through progressive alignment also reinforces generalisation abilities for known constructions. We assumed that the novel construction could have overgeneralised to the transitivity construction and that the better the novel construction is generalised, the worse the transitivity construction would be. It is actually not the observed pattern. It may be that mastering the novel construction better had led children to better discriminate between the transitive and the appearance scenes, and so to improve their performance for transitivity items when these items were not totally clear. Progressive alignment has already been shown to facilitate word extension in TD children for relational nouns and verbs (Childers et al., 2016; Gentner et al., 2011). However, progressive alignment has never been investigated in children with DLD, as far as we know. Here we demonstrate that progressive alignment is beneficial for construction generalisation, not only in TD children but also in children with DLD. This is consistent with studies that have reported a positive influence of similarity and a benefit of variability on generalisation in children with or without DLD (Aguilar et al., 2018; Casenhiser \& Goldberg, 2005; Leroy et al., 2014a; Perry et al., 2010; Plante et al., 2014). Progressive alignment is indeed a way to combine similarity and variability in the input provided. However, we did not find that children with DLD benefitted more from progressive alignment than their peers, as we expected. Some studies have shown that participants with language disorders needed more variability or similarity than their peers to generalise syntactic schemas (Leroy et al., 2014a; Von Koss Torkildsen et al., 2013). However, this was not found in our study, as participants with or without DLD benefitted from progressive alignment to the same extent. Lastly, high variability was not beneficial for construction generalisation, as both groups performed at chance level under this condition. Interestingly, children with DLD even performed below chance level when 
generalising the novel construction in the high variability condition. Actually, it is important to note that our two training conditions differed not only in the way variability was introduced, but also in their overall variability. The progressive alignment condition was indeed less variable than the high variability condition. It is therefore possible that high variability does not allow children to generalise novel constructions, while a lower variability introduced progressively can. Casenhiser and Goldberg (2005) already found that high variability did not allow children to generalise a NP-NP-V construction. However, other studies have shown a benefit of high variability against low variability, especially for children with DLD (Plante et al., 2014; Wonnacott et al., 2012). It is possible that in our study, variability was not sufficiently high and that increasing the number of training stimuli would have improved performance. It is also possible that adding a low variability condition would have demonstrated a benefit of high versus low variability. This could also have disentangled the influences of low variability and progressive alignment. Nevertheless, these results are in line with the theory according to which analogical comparisons lead to relational abstractions (Gentner \& Hoyos, 2017), and so to construction generalisation, as constructions are considered to be a kind of relational category (Goldwater, 2017). This study also confirms the idea that high similarity prompts analogical comparison, especially when similarity is introduced from the beginning and progressively diminishes, thus favoring alignment and abstraction (Gentner \& Hoyos, 2017; Gentner, Loewenstein, \& Hung, 2007; Loewenstein \& Gentner, 2001).

Finally, we wanted to examine the influence of inhibition on the ability to generalise a novel construction. Indeed, inhibition has crucial importance in the development of analogical reasoning, as it allows children to abstract schemas or categories while resisting to concrete features (Richland et al., 2006; Thibaut et al., 2010). Construction generalisation is performed through analogies (Bybee, 2010; Cordes, 2016), so it is likely that inhibition has an impact on the acquisition of novel constructions. This is exactly what we found, as inhibition, as measured by a classical Go/No-Go task, had an impact on the generalisation of novel construction items. This finding is consistent with a study showing that inhibition was related to the ability of TD children to move from perceptual to conceptual features in a word extension task (Snape \& Krott, 2018b). It seems, therefore, that inhibition helps compare several sentences to abstract a common relational structure without taking perceptual and concrete information into account. Inhibition could also play a role in inhibiting known constructions while children acquire novel constructions. Children with DLD have poor inhibition abilities compared to age-matched peers (Im-Bolter, Johnson, \& Pascual-Leone, 2006), so it is possible that this weakness in inhibition participates in the generalisation impairment observed in DLD. However, additional studies are needed to investigate this hypothesis, as in this study the two groups did not differ in their inhibition abilities or in their generalisation performance. Moreover, other measures of inhibition could be used to strengthen these data, especially since it was found that Stop-Signal tasks could measure context monitoring in response inhibition (Chatham et al., 2012).

\section{Conclusion and implications}

In this study, we evaluated the ability of children with or without DLD to generalise a novel construction. We compared the performance of children with DLD and children without language disorders matched by language level. Both groups performed similarly, which means that school-aged children with DLD have a construction generalisation ability that matches their general language level, at least when we consider receptive abilities. Moreover, to our knowledge, our study is the first to compare the impact of an input structured according to progressive alignment (in which variability is progressively introduced) with an input involving high variability in a construction generalisation task. 
We highlight the benefit of progressive alignment compared to high variability on construction generalisation in control children, but also in children with DLD. This could lead to promising trails in conducting interventions with children with DLD. Given that generalisation is a central aspect of clinical practices, progressive alignment and the progressive introduction of variability in the input provided could be implemented by clinicians to reduce the generalisation difficulties observed in DLD (Kamhi, 2014). Finally, we have also shown that inhibition, which is related to analogical reasoning (Richland et al., 2006; Thibaut et al., 2010), has an impact on the generalisation of novel constructions. Inhibition ability might, therefore, be a crucial tool to abstract schemas and categories based on conceptual or relational information rather than on concrete features. As inhibition is impaired in children with DLD (Im-Bolter et al., 2006), it is possible that this impairment participates in their weaknesses in generalisation. However, additional studies are needed to investigate this hypothesis. To conclude, this study provides new trails in the understanding of language acquisition in children with or without DLD. These data are particularly relevant for the study of DLD, as they could influence the way we think about interventions involving these children.

\section{References}

Aguilar, J. M., Plante, E., \& Sandoval, M. (2018). Exemplar variability facilitates retention of word learning by children with specific language impairment. Language, Speech, and Hearing Services in Schools, 49(1), 72-84.

Bishop, D. V., Snowling, M. J., Thompson, P. A., Greenhalgh, T., \& Catalise-2 Consortium. (2017). Phase 2 of CATALISE: A multinational and multidisciplinary Delphi consensus study of problems with language development: Terminology. Journal of Child Psychology and Psychiatry, 58(10), 1068-1080.

Bybee, J. (2010). Language, usage and cognition. Cambridge, England: Cambridge University Press.

Casenhiser, D., \& Goldberg, A. E. (2005). Fast mapping between a phrasal form and meaning. Developmental Science, 6, 500-508.

Chatham, C. H., Claus, E. D., Kim, A., Curran, T., Banich, M. T., \& Munakata, Y. (2012). Cognitive control reflects context monitoring, not motoric stopping, in response inhibition. PloS One, 7(2), e31546.

Childers, J. B., Parrish, R., Olson, C. V., Burch, C., Fung, G., \& McIntyre, K. P. (2016). Early verb learning: How do children learn how to compare events? Journal of Cognition and Development, 17(1), 41-66.

Collisson, B. A., Grela, B., Spaulding, T., Rueckl, J. G., \& Magnuson, J. S. (2015). Individual differences in the shape bias in preschool children with specific language impairment and typical language development: Theoretical and clinical implications. Developmental Science, 3, 373-388.

Conti-Ramsden, G., and Windfuhr, K. (2002). Productivity with word order and morphology: A comparative look at children with SLI and children with normal language abilities. International Journal of Language \& Communication Disorders, 37(1), 17-30.

Cordes, A. K. (2016). The roles of analogy, categorization, and generalization in entrenchment. In H.-J. Schmid (Ed.), Entrenchment and the psychology of language learning: How we reorganize and adapt linguistic knowledge (pp. 269-288). Berlin, Germany: De Gruyter.

Dunn, L. M., Theriault-Whalen, C. M., \& Dunn, L. M. (1993). Echelle de vocabulaire en images peabody. Toronto, Canada: Psychan. 
Gentner, D., Anggoro, F. K., \& Klibanoff, R. S. (2011). Structure mapping and relational language support children's learning of relational categories. Child Development, 82(4), 1173-1188.

Gentner, D \& Colhoun, J. (2010). Analogical processes in human thinking and learning. In B. Glatzeder, V. Goel, \& A. Müller (Eds.), Towards a theory of thinking (pp. 35-48). Berlin, Germany: Springer Berlin Heidelberg.

Gentner, D. \& Hoyos, C. (2017). Analogy and abstraction. Topics in Cognitive Science, 9(3), 672-693.

Gentner, D., Loewenstein, J., \& Hung, B. (2007). Comparison facilitates children's learning of names for parts. Journal of Cognition and Development, 8, 285-307.

Geurten, M., Catale, C., \& Meulemans, T. (2016). Involvement of executive functions in children's metamemory. Applied Cognitive Psychology, 30(1), 70-80.

Goldberg, A. E. (2003). Constructions: A new theoretical approach to language. Trends in Cognitive Sciences, 7(5), 219-224.

Goldwater, M. B. (2017). Grammatical constructions as relational categories. Topics in Cognitive Science, 9(3), 776-799.

Goldwater, M. B., Tomlinson, M. T., Echols, C. H., \& Love, B. C. (2011). Structural priming as structuremapping: Children use analogies from previous utterances to guide sentence production. Cognitive Science, 35(1), 156-170.

Hansson, K., \& Leonard, L. B. (2003). The use and productivity of verb morphology in specific language impairment: An examination of Swedish. Linguistics, 41(2), 351-380.

Im-Bolter, N., Johnson, J., \& Pascual-Leone, J. (2006). Processing limitations in children with specific language impairment: The role of executive function. Child Development, 77(6), 1822-1841.

Jones, M., \& Conti-Ramsden, G. (1997). A comparison of verb use in children with specific language impairment and their younger siblings. Journal of Speech, Language and Hearing Research, 40, 12981313.

Kamhi, A. G. (2014). Improving clinical practices for children with language and learning disorders. Language, Speech, and Hearing Services in Schools, 45(2), 92-103.

Khomsi, A. (2001). ELO: Evaluation du langage oral. Paris, France: ECPS.

Kotovsky, L., \& Gentner, D. (1996). Comparison and categorization in the development of relational similarity. Child Development, 67(6), 2797-2822.

Lecocq, P. (1996). L'ECOSSE: Une épreuve de compréhension syntaxico-sémantique. Villeneuve-d'Ascq, France: Presses Universitaires du Septentrion.

Leonard LB. (2014). Children with specific language impairment. Cambridge, MA: The MIT Press.

Leonard, L. B., Davis, J., \& Deevy, P. (2007). Phonotactic probability and past tense use by children with specific language impairment and their typically developing peers. Clinical Linguistics and Phonetics, $21,747-758$.

Leroy, S., Maillart, C., \& Parisse, C. (2014b). Analogical mapping across modalities in children with specific language impairment (SLI). Research in Developmental Disabilities, 35(9), 2158-2171. 
Leroy, S., Parisse, C., \& Maillart, C. (2014a). Le manque de généralisation chez les enfants dysphasiques : Une étude longitudinale. ANAE, 131, 1-9.

Leroy, S., Parisse, C., \& Maillart, C. (2012). Analogical reasoning in children with specific language impairment. Clinical Linguistics and Phonetics, 26(4), 380-395.

Lété, B., Sprenger-Charolles, L., \& Colé, P. (2004). Manulex: A grade-level lexical database from French elementary-school readers. Behavior Research Methods, Instruments, \& Computers, 36, 156-166.

Loewenstein, J., \& Gentner, D. (2001). Spatial mapping in preschoolers: Close comparisons facilitate far mappings. Journal of Cognition and Development, 2(2), 189-219.

Mathôt, S., Schreij, D., \& Theeuwes, J. (2012). OpenSesame: An open-source, graphical experiment builder for the social sciences. Behavior Research Methods, 44(2), 314-324.

Perry, L. K., Samuelson, L. K., Malloy, L. M., \& Schiffer, R. N. (2010). Learn locally, think globally: Exemplar variability supports higher-order generalization and word learning. Psychological Science, 21(12), 1894-1902.

Plante, E., Gómez, R., \& Gerken, L. (2002). Sensitivity to word order cues by normal and language/learning disabled adults. Journal of Communication Disorders, 35(5), 453-462.

Plante, E., Ogilvie, T., Vance, R., Aguilar, J. M., Dailey, N. S., Meyers, C., ... Burton, R. (2014). Variability in the language input to children enhances learning in a treatment context. American Journal of Speech-Language Pathology, 23, 530-545.

Psychology Software Tools, Inc. (2012). E-Prime 2.0. Retrieved from http://www.pstnet.com

Richland, L. E., Morrison, R. G., \& Holyoak, K. J. (2006). Children's development of analogical reasoning: Insights from scene analogy problems. Journal of Experimental Child Psychology, 94(3), 249-273.

Schmid, H.-J. (2016). A framework for understanding linguistic entrenchment. In H.-J. Schmid (Ed.), Entrenchment and the psychology of language learning: How we reorganize and adapt linguistic knowledge (pp. 9-35). Berlin, Germany: De Gruyter.

Snape, S., \& Krott, A. (2018a). The benefit of simultaneously encountered exemplars and of exemplar variability to verb learning. Journal of Child Language, 1-11.

Snape, S., \& Krott, A. (2018b). The role of inhibition in moving beyond perceptually focused noun extensions. First Language, 38(1), 95-108.

Souto, S. M., Leonard, L. B., Deevy, P., Fey, M. E., \& Bredin-Oja, S. L. (2016). Subordinate clause comprehension and tense/agreement inconsistency in children with specific language impairment. Journal of Communication Disorders, 62, 45-53.

Thibaut, J.-P., French, R., \& Vezneva, M. (2010). The development of analogy making in children: Cognitive load and executive functions. Journal of Experimental Child Psychology, 106(1), 1-19.

Tomasello, M. (2009). The usage-based theory of language acquisition. In E. L. Bavin (Ed.), The Cambridge handbook of child language (pp. 69-88). Cambridge, England: Cambridge University Press.

Vang Christensen, R., \& Hansson, K. (2012). The use and productivity of past tense morphology in specific language impairment: An examination of Danish. Journal of Speech, Language, and Hearing Research, 55, 1671-1689. 
Von Koss Torkildsen, J., Dailey, N. S., Aguilar, J. M., Gómez, R., \& Plante, E. (2013). Exemplar variability facilitates rapid learning of an otherwise unlearnable grammar by individuals with language-based learning disability. Journal of Speech, Language, and Hearing Research, 56(2), 618-629.

Wechsler, D., \& Naglieri, J. (2009). Echelle non verbale d'intelligence de Wechsler. Montreuil, France: ECPA.

Wonnacott, E., Boyd, J. K., Thomson, J., \& Goldberg, A. E. (2012). Input effects on the acquisition of a novel phrasal construction in 5 year olds. Journal of Memory and Language, 66(3), 458-478. 